Supporting Information

\title{
Biobased Microspheres Consisting of Poly(trans-anethole-co-maleic anhydride) Prepared by Precipitation Polymerization and Adsorption Performance
}

\author{
Yunbin Yuan, Xueyong Yong, Huanyu Zhang, Jianping Deng \\ State Key Laboratory of Chemical Resource Engineering and College of Materials \\ Science and Engineering, Beijing University of Chemical Technology, Beijing 100029, \\ China
}

Total number of pages: 8

Total number of figures: 12

Total number of tables: 3 


\section{Effects of monomer/initiator concentration ratio}
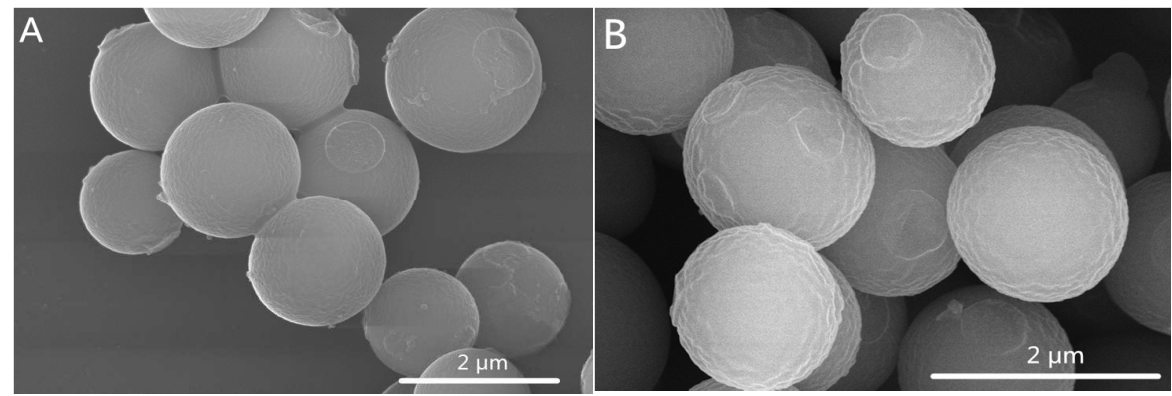

Figure S1. SEM images of poly(ANE-co-MAH) microspheres prepared with varied monomer/initiator concentration ratio: A, total monomer/AIBN, 80/1; $\mathrm{B}$, total monomer/AIBN, 40/1 (mol/mol). More information is presented in Table S1.

Table S1.Effect of initiator concentration. ${ }^{\mathrm{a}}$

\begin{tabular}{cccccc}
\hline $\begin{array}{c}{[\text { Total }} \\
\mathrm{M}] /[\mathrm{AIBN}] \\
(\mathrm{mol} / \mathrm{mol})\end{array}$ & $\begin{array}{c}\mathrm{Mn}^{\mathrm{b}} \\
(\mathrm{g} / \mathrm{mol})\end{array}$ & $\mathrm{Mw} / \mathrm{Mn}^{\mathrm{b}}$ & $\begin{array}{c}\text { Average Di- } \\
\operatorname{ameter}^{\mathrm{c}}(\mu \mathrm{m})\end{array}$ & $\mathrm{CV}^{\mathrm{c}}(\%)$ & $\begin{array}{c}\text { Yield }^{\mathrm{d}} \\
(\%)\end{array}$ \\
\hline $80 / 1$ & 64000 & 2.1 & 1.67 & 11.37 & 51.1 \\
$40 / 1$ & 30000 & 3.2 & 1.47 & 6.12 & 62.2
\end{tabular}

${ }^{\mathrm{a}}$ Polymerization conditions: $[\mathrm{ANE}]=[\mathrm{MAH}]=0.4 \mathrm{~mol} / \mathrm{L}, \mathrm{MEK} / n$-heptane $=4: 6(\mathrm{v} / \mathrm{v})$, $75{ }^{\circ} \mathrm{C}$ for 6 h. ${ }^{\mathrm{b}}$ Measuredby GPC. ${ }^{\mathrm{c}}$ Determined according to SEM images. ${ }^{\mathrm{d}}$ Determined by gravimetric method.

Table S1 and Figure S1 present the effects of monomer/initiator concentration ratio on the copolymerization and morphology of the microspheres. The microspheres with lower AIBN concentration showed lower yield (51.1\%) and higher CV (11.37\%). The polymer chains forming the microspheres possessed higher molecule weight over $60000 \mathrm{~g} / \mathrm{mol}$ and lower $\mathrm{Mw} / \mathrm{Mn}$ (2.1). When the amount of AIBN kept low, it resulted in a much higher Mn and fewer nucleation sites, which led to larger $(1.67 \mu \mathrm{m})$ but irregular particle size $(\mathrm{CV}, 11.37 \%)$. The lower AIBN concentration caused the decrease of the primitive nucleation numbers, which means higher particle size when monomer feed kept equal. The yield of the microspheres also decreased because of lower polymerization rate and the lower number of precipitate nucleations. We finally choose a moderate AIBN usage, namely, 40/1 of monomer/initiator ratio (in mol). 


\section{Effects of polymerization temperature}

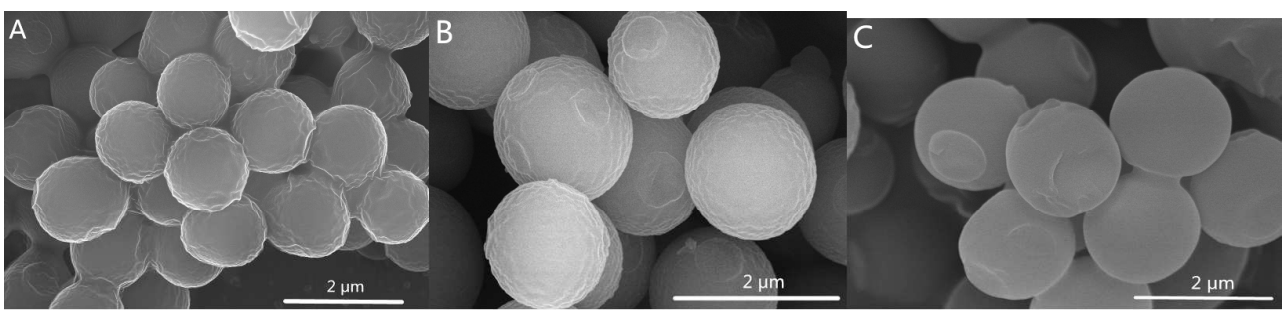

Figure S2. SEM images of poly(ANE-co-MAH) microspheres prepared at varied temperatures: A, 65; B, 75; and C, $80^{\circ} \mathrm{C}$. For more details, see Table S2.

Table S2. Effect of polymerization temperature. ${ }^{\mathrm{a}}$

\begin{tabular}{cccccc}
\hline $\begin{array}{c}\text { Temperature } \\
\left({ }^{\circ} \mathrm{C}\right)\end{array}$ & $\mathrm{Mn}^{\mathrm{b}}(\mathrm{g} / \mathrm{mol})$ & $\mathrm{Mw} / \mathrm{Mn}^{\mathrm{b}}$ & $\begin{array}{c}\text { Average Di- } \\
\operatorname{ameter}^{\mathrm{c}}(\mu \mathrm{m})\end{array}$ & $\mathrm{CV}^{\mathrm{c}}(\%)$ & Yield $^{\mathrm{d}}(\mathrm{wt} \%)$ \\
\hline 65 & 73000 & 3.1 & 1.41 & 7.09 & 22.2 \\
75 & 30000 & 3.2 & 1.47 & 6.12 & 62.2 \\
80 & 32000 & 3.6 & 1.73 & 2.89 & 61.9 \\
\hline
\end{tabular}

${ }^{a}$ Polymerization conditions: $[\mathrm{ANE}]=[\mathrm{MAH}]=0.4 \mathrm{~mol} / \mathrm{L},[\mathrm{AIBN}]=0.02 \mathrm{~mol} / \mathrm{L}$, $\mathrm{MEK} /$ heptane $=4: 6(\mathrm{v} / \mathrm{v}) .{ }^{\mathrm{b}}$ Determined by GPC. ${ }^{\mathrm{c}}$ Determined according to SEM images. ${ }^{\mathrm{d}}$ Determined by gravimetric method.

The effects of polymerization temperature on the formation of microspheres are presented in Table S2 and Figure S2. With the increase of temperature, the yield of the microspheres increased from around $20 \mathrm{wt} \%$ to over $60 \mathrm{wt} \%$, and simultaneously, the Mn of the copolymer chains decreased from 73000 to $30000 \mathrm{~g} / \mathrm{mol}$. As shown in Figure S2, although the $\mathrm{CV}$ of the microspheres obtained at high temperature are smaller $(\mathrm{CV}, 2.89 \%)$, their morphology is less desirable than the optimal group.

When the copolymerization was carried out at $65^{\circ} \mathrm{C}$, the amount of the generated free radicals was lower than that at $75^{\circ} \mathrm{C}$. This caused low polymerization rate and improvement in single polymer length, leading to microspheres in low yield and very poor morphology. When the polymerization temperature was increased to $80{ }^{\circ} \mathrm{C}$, coagulation improved a lot. Thus average diameter of the microspheres increased but with poor surface conditions. 


\section{NMR spectra of poly(ANE-co-MAH)}

The NMR spectra were measured by dissolving the microsphere in DMSO-d.
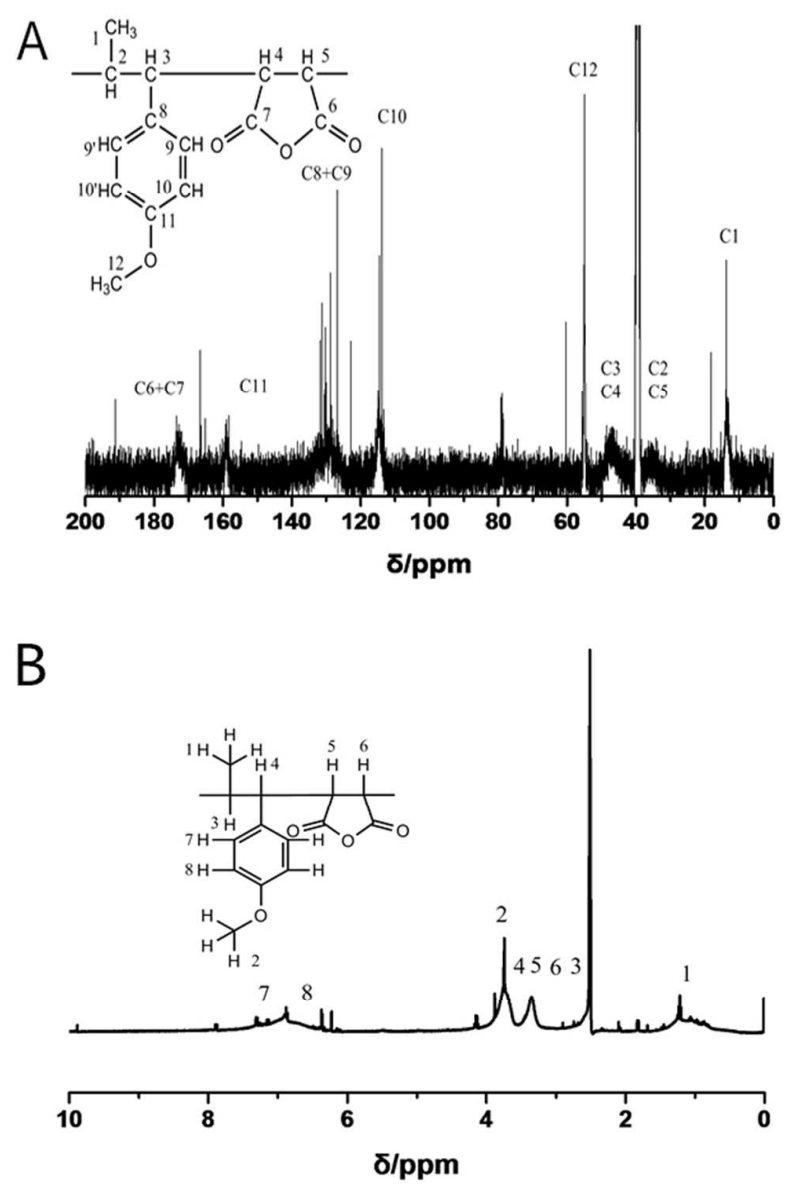

Figure S3. (A) ${ }^{13} \mathrm{C}$ NMR spectrum and (B) ${ }^{1} \mathrm{H}$ NMR spectrum of poly(ANE-co-MAH) microspheres. 


\section{DSC plot ofpoly(MAH-co-ANE) microspheres}

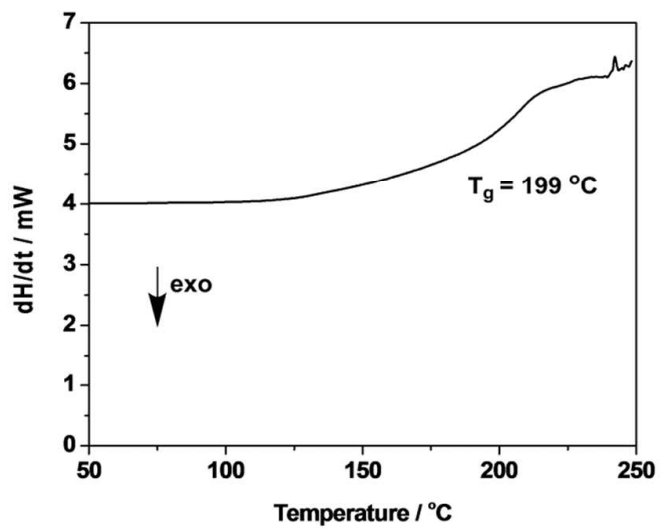

Figure S4. Typical DSC spectrum of non-crosslinked poly(ANE-co-MAH) microspheres. The $\mathrm{T}_{\mathrm{g}}$ of the poly(ANE-co-MAH) microspheres was around $199{ }^{\circ} \mathrm{C}$.

\section{The adsorption property of $\mathrm{Cr}$ (III)}

\section{Effects of microspheres amount}

The adsorption efficiency for $\mathrm{Cr}$ (III) ions as a function of absorbent amount was investigated systemically. The results are presented in Figure S5. The experimental data show that the removal efficiency of metal ions increased with increasing the amount of hydrolyzed microspheres. As increasing the absorbent from 0.5 to $4.0 \mathrm{~g} / \mathrm{L}$, the adsorption of $\mathrm{Cr}$ (III) ions increased from only $2 \%$ to $71 \%$, showing that increasing the absorbent amount provided more adsorption sites for the metal ions.

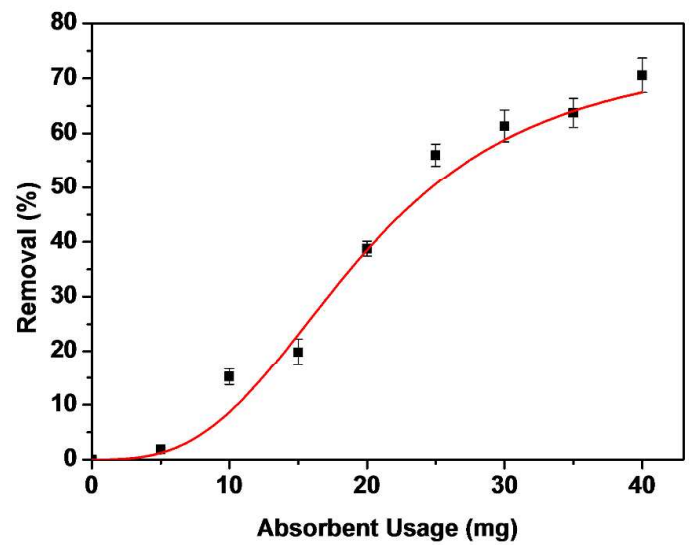

Figure S5. Effects of the hydrolyzed microspheres content on $\mathrm{Cr}$ (III) adsorption. Concentration of $\mathrm{Cr}(\mathrm{III}), 50 \mathrm{mg} / \mathrm{L} ; \mathrm{pH}, 5$; in water. 


\section{Effects of $\mathrm{Cr}$ (III) concentration}

As illustrated in Figure S6, when the concentration of Cr(III) increased, the removal percentage correspondingly reduced. The removal percentage decreased from $97 \%$ to only $20 \%$ when the concentration of $\mathrm{Cr}$ (III) increased from 10 to $100 \mathrm{mg} / \mathrm{L}$. The low removal percentage at high concentration of the adsorbate reveals that the adsorption capacity of the hydrolyzed microspheres, $q_{e}$, is limited. This phenomenon of limited adsorption capacity might be due to the fact that the active sites on the microspheres surface achieved adsorption saturation state prematurely.

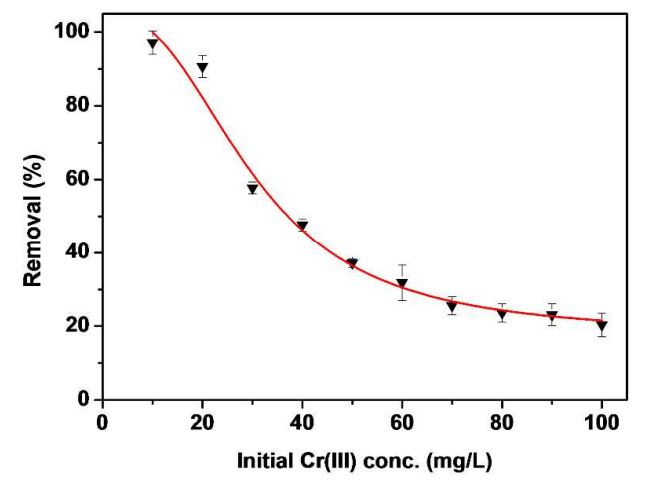

Figure S6. Effects of concentration of Cr(III) on adsorption by hydrolyzed microspheres. pH, 5; absorbent amount, $2.5 \mathrm{~g} / \mathrm{L}$.

\section{Adsorption quantity vs. equilibrium concentration $\left(q_{e}-c_{e}\right.$ curve)}

The $q_{e}-c_{e}$ curve is presented below. When $c_{e}$ increased, $q_{e}$ maintained at $9 \sim 10 \mathrm{mg} / \mathrm{L}$.

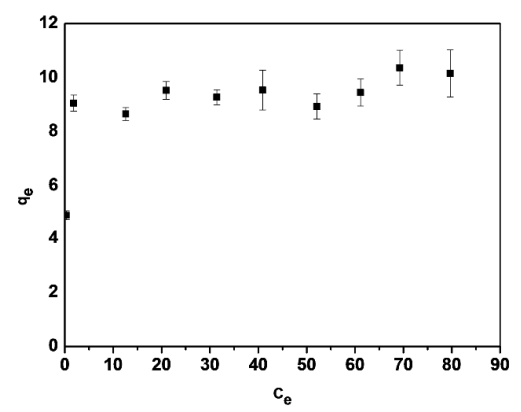

Figure S7. The relationship of adsorption quantity $\left(q_{\mathrm{e}}\right)$ and equilibrium concentration $\left(c_{\mathrm{e}}\right) \cdot \mathrm{pH}, 5$; absorbent amount, $2.5 \mathrm{~g} / \mathrm{L}$.

\section{Effects of pH}

As illustrated in Figure S8, when the $\mathrm{pH}$ of the adsorption system increased from 3 to 
6, the adsorption quantity by the microspheres increased from 3.26 to $9.8 \mathrm{mg} / \mathrm{L}$. The microspheres had a better adsorption quantity $\left(q_{e}\right)$ at a weak acid state. When $\mathrm{pH}$ decreased, the competition of $\mathrm{H}^{+}$with $\mathrm{Cr}$ (III) increased, leading to the decreased adsorption quantity. We did not investigate the adsorption at basic state because chromium hydroxide precipitated in this case.

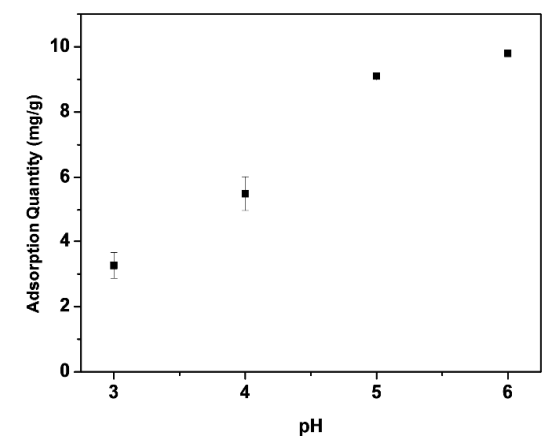

Figure S8. Effects of $\mathrm{pH}$ on $\mathrm{Cr}(\mathrm{III})$ adsorption by hydrolyzed microspheres. Concentration of $\mathrm{Cr}(\mathrm{III}), 50 \mathrm{mg} / \mathrm{L}$, absorbent amount, $2.5 \mathrm{~g} / \mathrm{L}$.

\section{FT-IR spectra of the microspheres after absorbing $\mathrm{Cr}$ (III)}

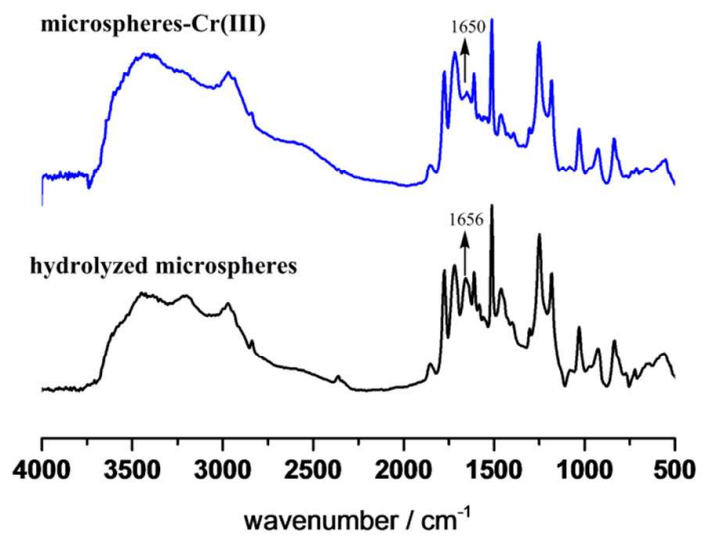

Figure S9. FT-IR spectra of hydrolyzed microspheres before and after the complexation with $\mathrm{Cr}(\mathrm{III})$.

As shown in Figure S5, after adsorbing Cr(III), the band at $1656 \mathrm{~cm}^{-1}$ shifted to lower frequency at about $1650 \mathrm{~cm}^{-1}$, indicating a stronger copolymer-metal bond formed between metal ions and carboxyl oxygen in carboxylate salts. 


\section{The adsorption property of methyl red}

\section{FT-IR spectra of the microspheres after absorbing methyl red}

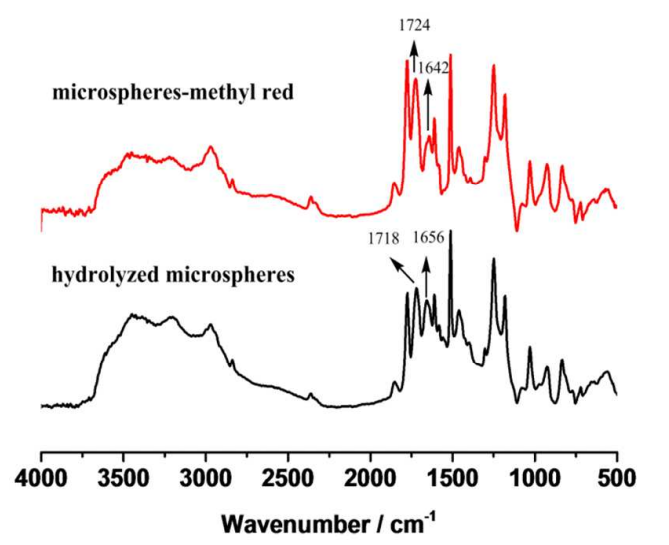

Figure S10. FT-IR spectra of hydrolyzed microspheres before and after the adsorption of methyl red.

After absorbing methyl red, the band at $1656 \mathrm{~cm}^{-1}$ shifted to low frequency at about $1642 \mathrm{~cm}^{-1}$, and the band at $1718 \mathrm{~cm}^{-1}$ shifted to high frequency at about $1724 \mathrm{~cm}^{-1}$. The result indicates the adsorption related to the carboxyl group in the hydrolyzed microspheres. The adsorption is completed through the electrostatic attraction between carboxyl groups on the hydrolyzed microspheres and N,N-dimethyl groups on methyl red.

\section{Effect of adsorbent amount on methyl red adsorption}

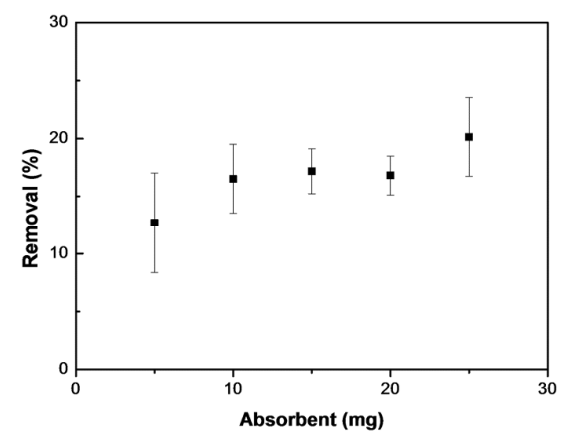

Figure S11. Effects of adsorbent amount on methyl red adsorption.

The phenomenon in Figure S11 indicates that the adsorption of methyl red in alcohol is different from the adsorption of $\mathrm{Cr}(\mathrm{III})$ in water. In the former, a complex adsorption process occurred. 


\section{Methyl red adsorption kinetic}

The pseudo-first-order kinetic and pseudo-second-order kinetic of methyl red adsorption are shown below.

Table S3. Kinetic models for adsorption of methyl red by hydrolyzed microspheres.

\begin{tabular}{llll}
\hline Parameters of pseudo-first-order kinetics & $k_{l}(1 / \mathrm{min})$ & $q_{e}(\mathrm{mg} / \mathrm{g})$ & $R^{2}$ \\
\hline & 0.321 & 13.90 & 0.5403 \\
\hline Parameters of pseudo-second-order kinetics & $k_{2}(\mathrm{~g} / \mathrm{mg} \mathrm{min})$ & $q_{e}(\mathrm{mg} / \mathrm{g})$ & $R^{2}$ \\
\hline & 0.043 & 21.23 & 0.9581 \\
\hline
\end{tabular}
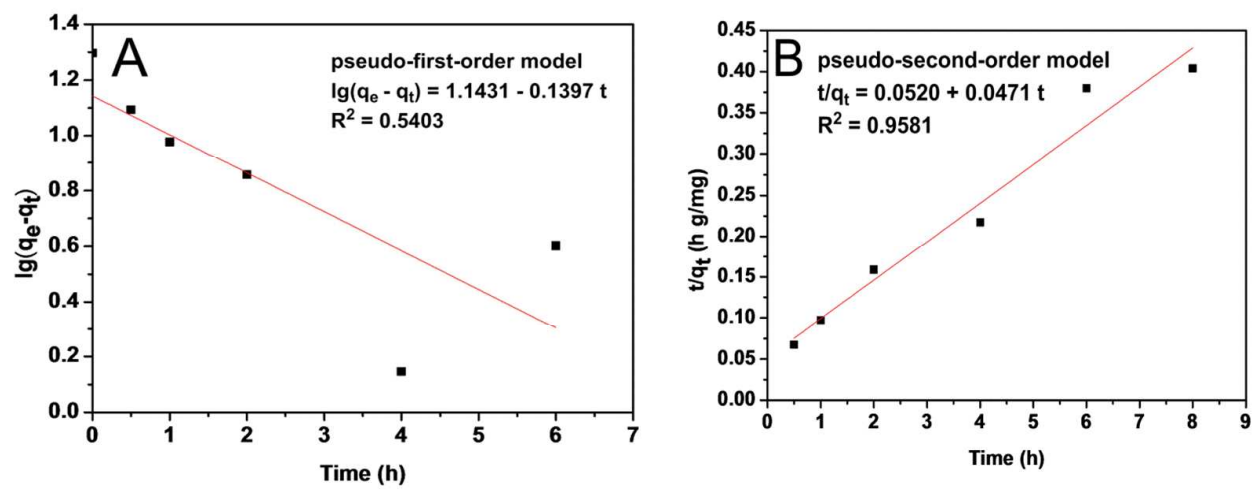

Figure S12. Kinetic model for adsorption of methyl red by the microspheres: A, pseudo-first-order model; B, pseudo-second-order model.

The pseudo-first-order kinetic of methyl red adsorption did not fit well, $R^{2}=0.5403$. However, the pseudo-second-order kinetic of methyl red adsorption can be fitted as into a straight line. It means the adsorption of methyl red was completed by some specific functional groups. Combining with FT-IR spectra, the adsorption was considered proceeding through the electrostatic attraction between carboxyl groups on the hydrolyzed microspheres and $\mathrm{N}, \mathrm{N}$-dimethyl groups on methyl red. 